\title{
Interferências da forma urbana na dinâmica da temperatura intra-urbana
}

\author{
Patricia R. C. Drach e Rohinton Emmanuel \\ School of Engineering and Built Environment - SEBE, Glasgow Caledonian \\ University, Glasgow - G4 OBA, United Kingdom. E-mail: patricia.drach@gmail.com, \\ rohinton.emmanuel@gcu.ac.uk
}

Artigo revisto recebido a 27 de Setembro de 2014

\begin{abstract}
Resumo. As perspectivas de mudanças climáticas e suas possíveis consequências recomendam o desenvolvimento de estratégias para mitigar problemas relacionados ao sobreaquecimento urbano. O presente estudo tem como objetivo examinar a interferência da forma urbana, aferida pela Fracção de Céu Visível (Sky View Factor, SVF), sobre as variações na temperatura intra-urbana na cidade de Glasgow, Reino Unido, uma cidade de clima frio. 49 pontos de medição foram locados no centro da cidade e foram desenvolvidas 31 campanhas de coleta de dados, durante a primavera e o verão de 2013. Para cobrir uma grande área dentro de um tempo relativamente curto, foi utilizado o método de 'transecto' com rotas prédeterminadas, a pé e de bicicleta. O software ArcGIS foi utilizado para visualização dos resultados. Os resultados indicam que a variação da diferença da temperatura intra-urbana está fortemente relacionada à estabilidade atmosférica, sugerindo que esta tem realmente um importante efeito nessa variação. O estudo conseguiu apontar ainda, conforme esperado, que a vegetação $e$ os materiais de cobertura urbana desempenham um papel importante, interferindo no clima local. O conhecimento das interferências nas variações de temperatura local pode ser mais um aliado na elaboração de estratégias apropriadas para lidar com os problemas do sobreaquecimento urbano.
\end{abstract}

Palavras-chave: temperatura intra-urbana, forma urbana, Fracção de Céu Visível, desenho urbano, estabilidade / instabilidade atmosférica.

Os efeitos do aquecimento urbano estão presentes em todos os climas e podem ser observados na formação da Ilha de Calor Urbana (ICU) e na variação da temperatura intra-urbana. $\mathrm{O}$ objeto deste artigo é o estudo da variação da temperatura intra-urbana e sua relação com a forma urbana e a instabilidade/estabilidade atmosférica.

A ilha de calor é uma anomalia térmica positiva onde a temperatura média da baixa atmosfera de uma determinada área urbana se torna mais elevada do que a das regiões circundantes não urbanizadas. As variações térmicas podem ser de vários graus celsius e ocorrem basicamente devido às diferenças de absorção / emissão de radiação infravermelha entre as regiões edificadas e impermeabilizadas e aquelas não construídas (Corbella e Yannas, 2003; Monteiro et al., 2012a).

As variações da temperatura intra-urbana estão relacionadas com as diferenças observadas na temperatura do ar no meio urbano. Esses processos são significativamente alterados, entre outras, pelas seguintes características: transformação de energia solar em calorífica, que resulta da forma urbana e da proliferação de superfícies e materiais muito diversos quanto aos materiais como quanto à geometria; diminuição de áreas verdes e impermeabilização do solo; e presença de fontes antrópicas de calor e humidade como a utilização de condicionadores de ar, 
refrigeradores e queima de combustível por automóveis e indústrias.

Apesar do problema de sobreaquecimento urbano ser reconhecido e estudado em locais de climas quentes, em cidades de climas frios as suas implicações têm sido, por vezes, assumidas como um fator positivo. $\mathrm{Na}$ década de 1960, por exemplo, o fenômeno de ilha de calor urbano de Londres foi apresentado com muitas conotações positivas. Dentre elas podem ser apontadas, uma estação de plantio e coleita mais longa, menor necessidade de aquecimento, menos gastos com degelo em vias férreas, entre outra (Chandler, 1965). Contudo, atualmente, ou seja, passados menos de 50 anos, o sobreaquecimento causado pelo efeito de ICU já vem sendo identificado como um problema (GLA, 2006; Kolokotroni e Giridharan, 2008; entre outros) e as políticas para mitigar as suas consequências promovendo medidas de adaptação tem vindo a ser postas em prática (GLA, 2011).

A importância de atenuar o efeito da ICU tem vindo a ser cada vez mais assinalada como uma prioridade estratégica. O global e crescente processo de urbanização representa uma intensificação dos riscos das alterações climáticas em relação às cidades que normalmente já vêm comprometendo as condições ambientais. Segundo o World Urbanization Prospects (UN, 2011), as projeções da dinâmica de populações urbanas e rurais até o ano de 2050 apontam perspectivas de intensificação da ocupação urbana (Figura 1). Este fato é particularmente grave nas áreas em vias de desenvolvimento, onde a curva de ocupação da área urbana é contraposta por uma curva descendente na área rural.

Uma vez que as cidades interferem e sofrem a interferência do meio ambiente, atentar para as opções de planejamento urbano apropriadas pode ajudar a melhorar o problema de sobreaquecimento urbano e a desenvolver meios de adaptar as cidades para lidar com os riscos relacionados com as futuras alterações climáticas (Kleerekoper et al., 2012). Em cidades de clima frio, para lidar com problemas que envolvem $o$ aquecimento urbano (Stone et al., 2012) são necessárias ações voltadas tanto para o uso do calor como um recurso no inverno bem como para amenizar suas consequências

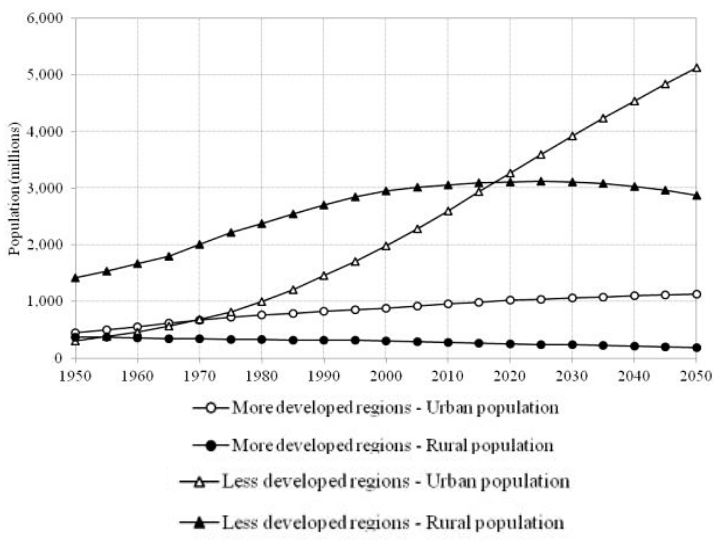

Figura 1. Populações urbanas e rurais do mundo: 1950-2050 (fonte: UN, 2011).

negativas no verão. Além disso, diante dos novos cenários de mudanças climáticas, serão também necessárias, intervenções para mitigação das referidas alterações, através da redução de emissão de gases de efeito estufa.

No entanto, as estratégias urbanas de adaptação às alterações climáticas vêm sendo abordadas (Hebbert e Jankovic, 2013) com planos de ação específicos para cada cidade fazer frente aos riscos decorrentes das manifestações de mudança climática. Em particular, o desenvolvimento de estudos relacionados com a forma urbana como um dos possíveis caminhos para se adaptar às mudanças climáticas são raros (Shimoda, 2003; Amorim et al., 2013).

A exploração da eficácia das formas urbanas pode apontar a importância do planeamento $\mathrm{da}$ forma urbana visando reduzir o risco de sobreaquecimento atenuando as suas consequências negativas.

Dado o crescente interesse pelas medidas de adaptação às alterações climáticas, bem como o aumento do uso de modelos para avaliar a eficácia de diversas ações de adaptação (Tomlinson et al., 2012), tais avaliações deveriam descrever tanto os efeitos urbanos, bem como a interferência dos efeitos atmosféricos sobre os microclimas. Um maior conhecimento das dinâmicas envolvidas na forma urbana pode ser ainda um grande aliado para diferenciação mais precisa dos efeitos relacionados às interferências do desenho urbano daqueles causados por condições atmosféricas (Monteiro et al., 2012b).

$\mathrm{O}$ objetivo do presente artigo é precisamente examinar o efeito da forma urbana sob diversas condições atmosféricas 
nas variações da temperatura intra-urbana, na cidade de Glasgow, Reino Unido. De acordo com a classificação de Koeppen-Geiger, Glasgow é uma cidade caracterizada por um clima temperado (Cfb), suavizado pela influência marítima. As condições atmosféricas são avaliadas e classificadas utilizando o critério Pasquill-Gifford-Turner modificado, e a forma urbana é aferida pelo Sky View Factor (SVF). No estudo, foi considerada a variedade da forma urbana observada no centro da cidade, associada à presença de diferentes componentes da paisagem urbana para identificar seus efeitos no aquecimento local.

\section{Estado da arte}

Kershaw et al. (2010) apresentaram uma metodologia para avaliar o efeito da ICU em diversos cenários das projeções climáticas realizadas para o Reino Unido. As implicações, no futuro, da ICU em relação ao conforto, energia e saúde para uma cidade de um tipo de clima frio como Londres, por exemplo, já foram descritas por Mavrogianni et al. (2011).

Os estudos de Drach (2007) sublinham a capacidade dos elementos de forma urbana de influenciarem as dinâmicas de ventilação e, consequentemente, da temperatura no interior dos espaços urbanizados.

\section{Efeito da forma urbana}

Em zonas frias, o efeito da geometria urbana na criação de microclimas e na definição da forma e da magnitude da ICU pode ser medida pelo SVF. Uma primeira tentativa de estabelecer uma ligação entre o SVF e o ICU, utilizando elementos objetivos foi relatada por Oke (1981). Uma análise detalhada dos esforços subsequentes foi desenvolvida por Unger (2004).

Enquanto Unger (2009) encontrou relações frágeis e contraditórias àcerca da relação entre o SVF e a temperatura do ar no ambiente urbano, noutros estudos, por exemplo, em Gotemburgo na Suécia, foram encontradas relações bastante consistentes $\left(\mathrm{R}^{2}=0,78\right)$, em algumas áreas específicas da cidade durante as campanhas de medição (Svensson, 2004).
Todavia, levando em conta medições durante períodos de tempo mais extensos (um ano), e sobre uma área maior, como por exemplo toda a área urbanizada de Szeged, na Hungria (Unger, 2004), os resultados mostraram uma relação bastante mais fraca $\left(\mathrm{R}^{2}=0,47\right)$. Por esse motivo Unger (2009) enfatizou a importância da escala e chamou a atenção tanto para a necessidade de delimitar a área de estudo (para estabelecer uma melhor correlação) como de selecionar a escala apropriada de trabalho para verificar uma relação entre o $\quad$ SVF e significativa.

\section{Aquecimento urbano e instabilidade atmosférica}

$\mathrm{Na}$ literatura sobre os efeitos de ICU são encontrados trabalhos em que as medições foram feitas relatando também as condições de estabilidade atmosférica. Dentre os estudos que exploram o efeito de fatores de forma urbana, bem como as condições de estabilidade meteorológica pode ser citado aqui, a título de exemplo, o exposto por Unger et al. (2001) em estudo realizado para a cidade de Szeged. Explorando o uso do solo e aspectos meteorológicos de ICU nesta cidade, Unger et al. (2001) relataram uma forte relação entre o aumento da temperatura urbana e a distância do centro da cidade, bem como a relação com a área construída, mas as condições de estabilidade meteorológica não apresentaram efeito significativo sobre a intensidade das ilhas de calor urbanas.

Nos últimos anos ganhou importância a análise mais cuidadosa das condições atmosféricas (Lee et al. 2009, Holmer et al. 2012) e dos padrões sinóticos (Kolokotsa et al., 2009; Lai e Cheng 2009), necessidade esta impulsionada pelo reconhecimento da influência de tais padrões nas medições das ICU. Mirzaei e Haghighat (2010), ao discutir as fragilidades das técnicas de monitorização e de simulação de ilhas de calor urbanas, apontam a grande importância do conhecimento dos processos de resolução do sistema climático a grande escala para a formação das ICU. Foi o que procuraram Kruger e Emmanuel (2013) para estimarem os efeitos atmosféricos sobre as ICU, bem como as diferenças das temperaturas intra- 
urbanas, concluindo que as diferenças nas temperaturas intra-urbanas, assim como o aquecimento em relação aos locais urbanos específicos foram acentuados quando levada em conta a estabilidade atmosférica. Além disso, a relação entre SVF e aquecimento local foi mais pronunciada sob condições atmosféricas estáveis.

\section{Métodos e materiais}

A variação da temperatura local foi medida com o apoio da estação meteorológica de referência. A estação meteorológica Davis Vantage Pro2 foi utilizada como estação de referência e instalada no campus da Glasgow Caledonian University GCU $\left(55^{\circ} 51^{\prime}\right.$ $57.294 " \mathrm{~N}, 4^{\circ} 15^{\prime} 0.2628 " \mathrm{~W}, 138 \mathrm{~m}$ amsl). Trata-se de um equipamento wireless composto de duas partes: conjunto de sensores (sensor de temperatura e humidade do ar, piranômetro de silício, anemômetro de copo com pá de vento e coletor de água de chuva) e uma consola digital (data logger) usada para o armazenamento de dados. A monitorização das variáveis climáticas foi realizada continuamente e os registos armazenados a cada 15 minutos. As informações sobre a localização da estação meteorológica de referência (denominada 1s), da imagem da lente de olho de peixe, do SVF e da trajetória solar, são apresentados na Tabela 1. Na Tabela 2 estão indicadas as características de cada sensor utilizado nas medições, ou seja, os sensores localizados na estação de referência e aqueles utilizados em pontos fixos e nos transectos.

As medições foram efetuadas em vários pontos da cidade através de data loggers fixos e móveis (transectos). Foram demarcados seis pontos de medição fixos e 42 pontos de medição móveis. Os sensores de temperatura e humidade (Tinytag TGP4500) foram transportados com coberturas de proteção para impedir que sejam atingidos por radiação solar direta e difusa, além de oferecer proteção em caso de precipitação, muito comum na região. São de cor branca e possuem aberturas apropriadas para permitir a ventilação no interior dos sensores/registradores de dados.

\section{Forma urbana}

Foram selecionados pontos representativos da forma urbana de Glasgow para avaliar e comparar os resultados de diferentes utilizações do espaço urbano. $\mathrm{O}$ objetivo almejado foi a obtenção de informação suficientemente diversificada e representativa da dinâmica de variação de temperatura dentro do centro da cidade

No início, a região foi analisada através de uma simples caminhada no centro da cidade de Glasgow e os pontos foram determinados por observação visual intuitiva. Durante a caminhada a intenção foi determinar diferenças marcantes na forma urbana como, por exemplo, ruas extremamente estreitas, áreas abertas, proximidade do Rio Clyde, canyons urbanos, praças com e sem vegetação, entre outros. Posteriormente, as imagens das áreas selecionadas dentre as visitadas foram fotografadas com uma objetiva 'olho de peixe' (SIGMA 4,5 milímetros f $2.8 \mathrm{EX}$ ). A partir dessas imagens foram calculados os SVF e as trajetórias solares, utilizando a ferramenta computacional RayMan Pro (desenvolvido por Matzarakis et al., 2010).

Tabela 1. Estação meteorológica de referência - Glasgow Caledonian University (1s)

\begin{tabular}{|c|c|c|c|}
\hline Coordenadas e FVC & $\begin{array}{c}\text { Imagem com lente } \\
\text { olho de peixe }\end{array}$ & $\begin{array}{c}\text { Máscara de obstrução } \\
\text { do entorno }\end{array}$ & Trajetória solar \\
\hline $\begin{array}{l}\text { Latitude: } 55^{\circ} 51^{\prime} 57.294^{\prime \prime} \\
\text { Longitude: } 4^{\circ} 15^{\prime} \\
0.2628^{\prime \prime} \mathrm{W}\end{array}$ & & & \\
\hline FVC 0.774 & & & \\
\hline
\end{tabular}


Tabela 2. Características do equipamento utilizado nas medições

\begin{tabular}{|c|c|c|c|c|}
\hline Sensor & Posicionamento & $\begin{array}{c}\text { Resolução por } \\
\text { unidade de medida }\end{array}$ & $\begin{array}{l}\text { Intervalo de } \\
\text { medição }\end{array}$ & Precisão \\
\hline $\begin{array}{c}\text { Temperatura do } \\
\text { ar }\end{array}$ & $\begin{array}{l}\text { Estação meteorológica } \\
\text { de referência }\end{array}$ & $\begin{array}{c}0,1^{\circ} \mathrm{C} \text { ou } 1{ }^{\circ} \mathrm{C} \\
\text { (user-selectable) }\end{array}$ & $-40^{\circ} \mathrm{a}+65^{\circ} \mathrm{C}$ & $\begin{array}{c} \pm 0,5^{\circ} \mathrm{C} \text { acima de } \\
20^{\circ} \mathrm{F}\left(-7^{\circ} \mathrm{C}\right)\end{array}$ \\
\hline Umidade do ar & $\begin{array}{c}\text { Estação meteorológica } \\
\text { de referência }\end{array}$ & $1 \%$ & 1 a $100 \%$ & $\begin{array}{c} \pm 3 \%(0-90 \%), \pm 4 \% \\
(90-100 \%)\end{array}$ \\
\hline $\begin{array}{l}\text { Velocidade do } \\
\text { ar }\end{array}$ & $\begin{array}{c}\text { Estação meteorológica } \\
\text { de referência }\end{array}$ & $0,4 \mathrm{~m} / \mathrm{s}$ & $1 \mathrm{a} 80 \mathrm{~m} / \mathrm{s}$ & $\pm 1 \mathrm{~m} / \mathrm{s}$ \\
\hline $\begin{array}{l}\text { Direção do } \\
\text { vento }\end{array}$ & $\begin{array}{c}\text { Estação meteorológica } \\
\text { de referência }\end{array}$ & $22,5^{\circ}$ & $0-360^{\circ}$ & $\pm 3^{\circ}$ \\
\hline Radiação solar & $\begin{array}{c}\text { Estação meteorológica } \\
\text { de referência }\end{array}$ & $1 \mathrm{~W} / \mathrm{m} 2$ & $\begin{array}{c}0 \text { a } 1800 \\
\mathrm{~W} / \mathrm{m} 2\end{array}$ & $\pm 5 \%$ \\
\hline $\begin{array}{l}\text { Temperatura do } \\
\text { ar (Tinytag } \\
\text { TGP-4500) }\end{array}$ & $\begin{array}{c}\text { Transectos: pontos } \\
\text { fixos e percursos a pé e } \\
\text { de bicicleta }\end{array}$ & $0,01^{\circ} \mathrm{C}$ & $\begin{array}{l}-25^{\circ} \mathrm{C} \mathrm{a} \\
+85^{\circ} \mathrm{C}\end{array}$ & $\pm 0,45^{\circ} \mathrm{C}$ \\
\hline
\end{tabular}

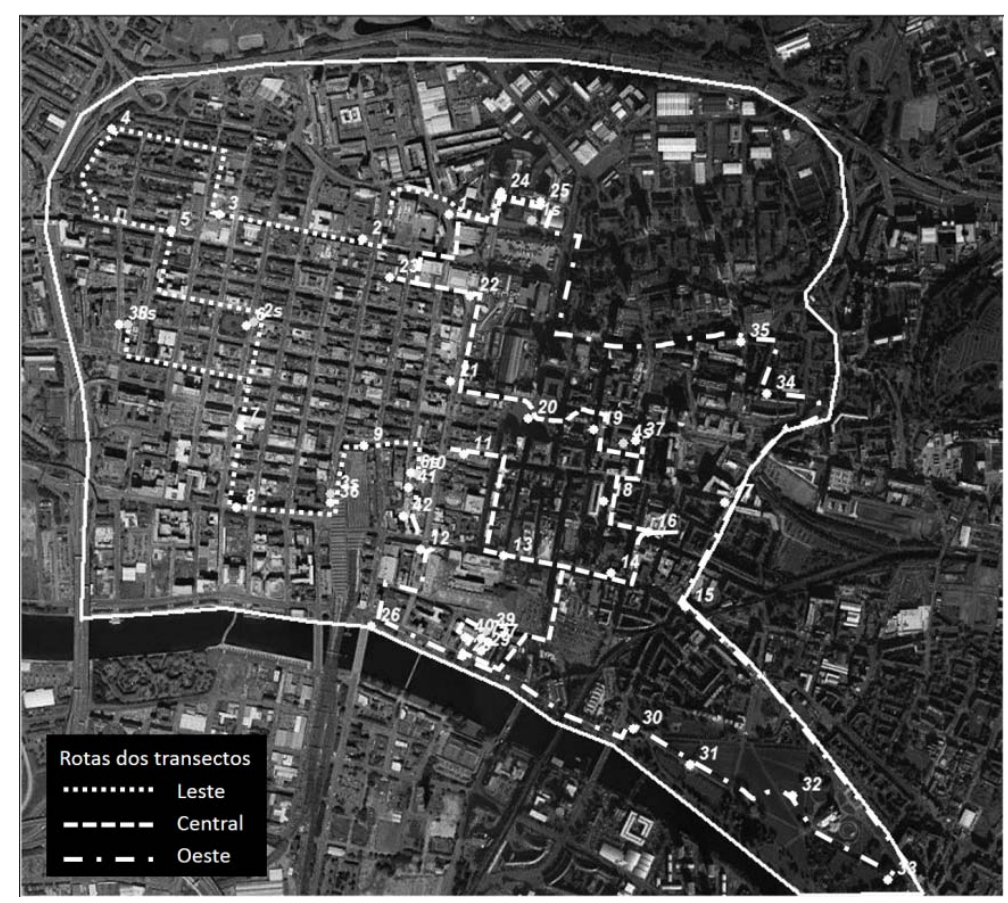

Figura 2. Localização dos pontos de medição no centro da cidade de Glasgow.

A partir da análise das imagens e dos valores de SVF, foram selecionados os pontos mais representativos da diversidade de uso do solo urbano necessária para a análise.

Assim, levando em conta a diferenciação da forma urbana, os pontos de medição selecionados foram os que evidenciavam diferenças marcantes na forma urbana que podem interferir no microclima local. Para a localização de cada ponto de medição, foi usado um GPS (GPS Garmin MAP) com o intuito de fornecer a localização precisa das coordenadas geográficas de cada um dos pontos e possibilitar que a experiência pudesse ser repetida sempre que necessário.

Com a informação das coordenadas 
Tabela 3. Localização dos sete pontos estacionários (2s ... 7s)

\begin{tabular}{|c|c|c|c|}
\hline Coordenadas e FVC & $\begin{array}{l}\text { Imagem com lente } \\
\text { olho de peixe }\end{array}$ & $\begin{array}{c}\text { Máscara de } \\
\text { obstrução do } \\
\text { entorno }\end{array}$ & Trajetória solar \\
\hline \multicolumn{4}{|l|}{ Blythswood Square (2s) } \\
\hline & \multicolumn{3}{|c|}{ Longitude: $4^{\circ} 15^{\prime} 44.1288^{\prime \prime} \mathrm{W}$} \\
\hline \multicolumn{4}{|l|}{ FVC: 0.017} \\
\hline \multicolumn{4}{|l|}{ City Council - Hope St (3s) } \\
\hline & \multicolumn{3}{|c|}{ Longitude: $4^{\circ} 15^{\prime} 33.0804^{\prime \prime} \mathrm{W}$} \\
\hline \multicolumn{4}{|l|}{ City Council - Montrose St (4s) } \\
\hline & \multicolumn{3}{|c|}{ Longitude: $4^{\circ} 14^{\prime} 46.4274^{\prime \prime} \mathrm{W}$} \\
\hline \multicolumn{4}{|l|}{ City Council - Elmbank St (5s) } \\
\hline \multicolumn{2}{|l|}{ Latitude: $55^{\circ} 51^{\prime} 48.618 " \mathrm{~N} /$} & & \\
\hline \multicolumn{4}{|l|}{ FVC: 0.205} \\
\hline \multicolumn{4}{|l|}{ Lighthouse - Mitchell Ln (6s) } \\
\hline \multicolumn{4}{|l|}{$\begin{array}{l}\text { Latitude: } 55^{\circ} 51^{\prime} 35.445^{\prime \prime} \mathrm{N} / \\
\text { Longitude: } 4^{\circ} 15^{\prime} 20.1132^{\prime \prime} \mathrm{W}\end{array}$} \\
\hline \multicolumn{4}{|l|}{ FVC: 0.042} \\
\hline \multicolumn{4}{|l|}{ St Andrew’s Cathedral (7s) } \\
\hline \multicolumn{4}{|l|}{$\begin{array}{l}\text { Latitude: } 55^{\circ} 51^{\prime} 20.5122^{\prime \prime} \mathrm{N} / \\
\text { Longitude: } 4^{\circ} 15^{\prime} 8.7762^{\prime \prime} \mathrm{W}\end{array}$} \\
\hline FVC: 0.440 & & & \\
\hline
\end{tabular}


Tabela 4. Variações da forma urbana (imagens de quatro dos 42 pontos de medição)

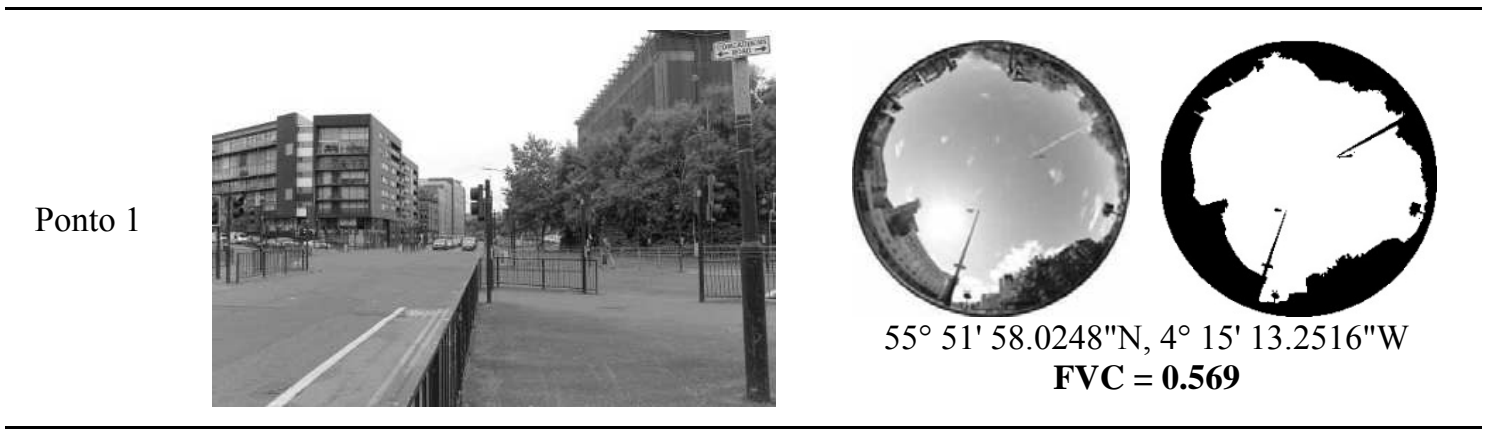

Ponto 10
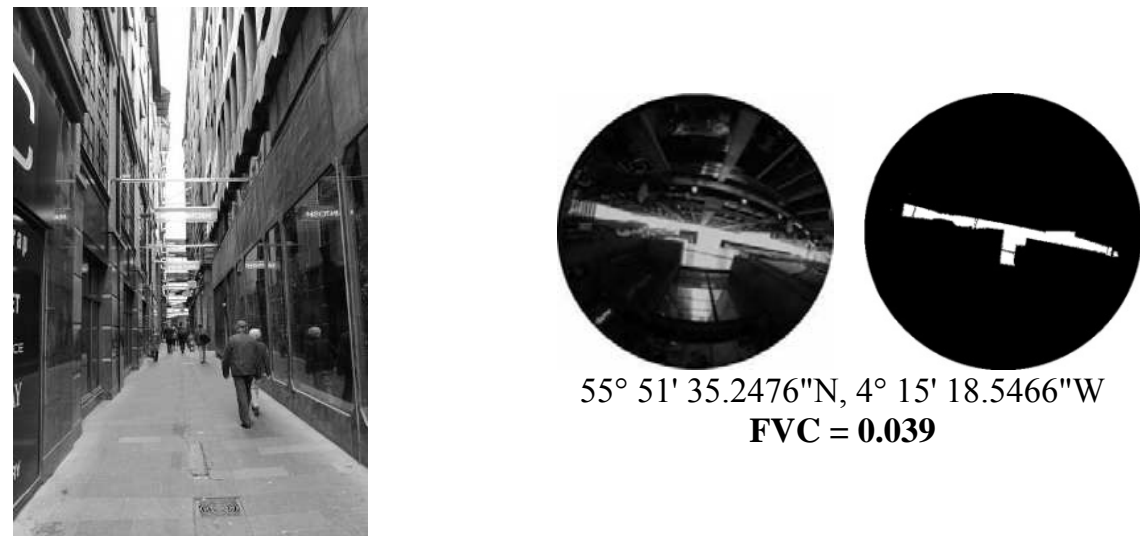

$55^{\circ} 51^{\prime} 35.2476^{\prime \prime} \mathrm{N}, 4^{\circ} 15^{\prime} 18.5466^{\prime \prime} \mathrm{W}$

FVC $=0.039$

Ponto 22
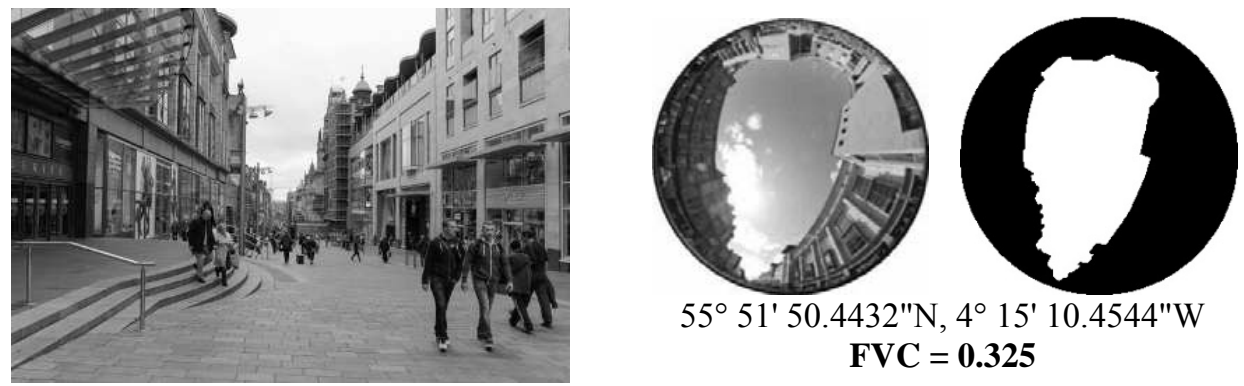

$55^{\circ} 51^{\prime} 50.4432 " \mathrm{~N}, 4^{\circ} 15^{\prime} 10.4544^{\prime \prime} \mathrm{W}$

FVC $=0.325$

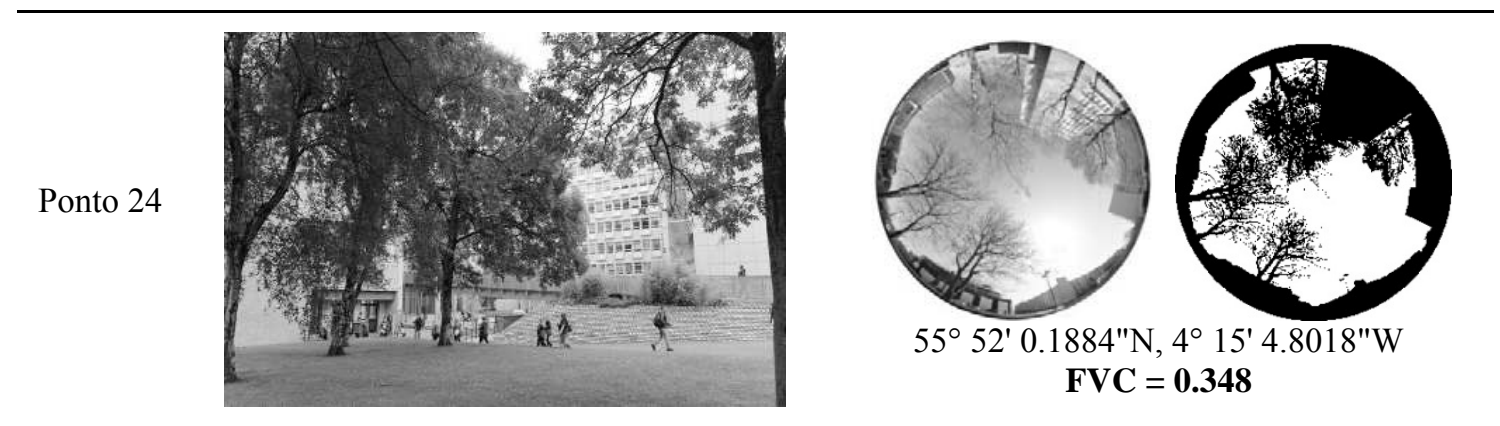

geográficas, das imagens recolhidas com a lente olho de peixe, das trajetórias solares e dos SVF foi possível determinar os pontos apropriados para localizar os sensores climáticos. No mapa do centro da cidade de Glasgow são apresentados os 49 pontos de medição (Figura 2).
Representação espacial das variações de temperatura

Os seis pontos de medição fixos são apresentados na Tabela 3. Quatro pontos móveis foram escolhidos (Tabela 4), dentre quarenta e dois utilizados, para representar as variações da forma urbana e a 
diversidade entre os pontos selecionados. Pode ser observada, além da variação do valor do SVF, a diversidade de cenários existente.

\section{Protocolo das medições}

Foram efetuadas, durante a primavera e o verão de 2013, 31 campanhas de coleta de dados, compreendendo os meses de Maio, Junho, Julho e Agosto. Para que a coleta de dados fosse capaz de abranger todo o centro da cidade de Glasgow num curto intervalo de tempo (uma hora) foi adotado o método de 'transectos pedonais'. Para tal foram definidas três rotas pré-determinadas (Figura 2) percorridas a pé e de bicicleta-Meteobike (Figura 3). A bicicleta tornou-se uma importante ferramenta de apoio, principalmente por causa da distância a percorrer dentro do Green Park de Glasgow.

Três rotas foram definidas tendo a Buchanan Street, rua de pedestres que divide o centro da cidade de Glasgow, como referência: uma central, uma na direção oeste e outra na direção leste incluindo aí o parque Glasgow Green. As três rotas têm o Ponto 25, situado na Glasgow Caledonian University, próximo à estação de referência, como ponto partida e o Ponto 10 , próximo à Buchanan Street, como término do percurso. Os trajetos das três rotas podem ser observados na Figura 2.

Antes de iniciar as medições, os sensores de temperatura e umidade são colocados ao ar livre por 20 minutos. Em cada ponto de medição são efetuadas paragens de 2 minutos. Os medidores foram programados para efetuarem registros em intervalo de 10 em 10 segundos. As quatro primeiras medidas de cada ponto são desprezadas para garantir que o registrador esteja estabilizado.

Conta-se, portanto, com oito medições para calcular a média para cada ponto. As campanhas de medição têm início às 14:30 horas, horário local, para estarem próximas da temperatura maxima diária, que tipicamente ocorre às 15:00 horas, e finaliza por volta das 15:30 horas, durando, portanto, aproximadamente uma hora. $\mathrm{O}$ intervalo de uma hora foi estabelecido para que as variações de temperatura observadas

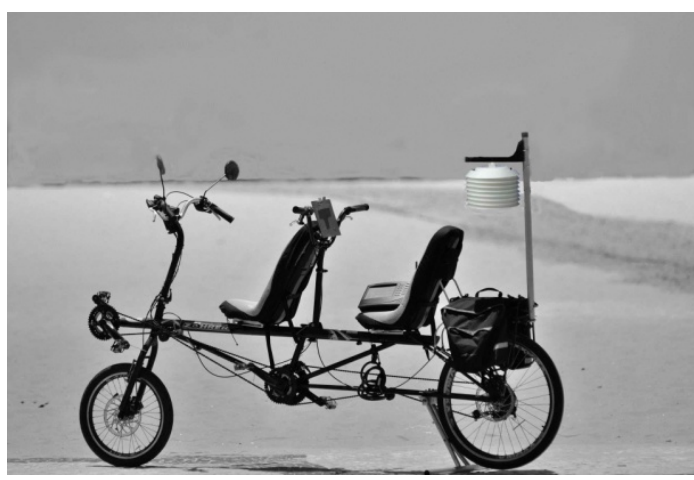

Figura 3. Bicicleta utilizada durante as medições, Meteobike.

pudessem ser atribuídas apenas às variações da forma urbana. Para validar os dados recolhidos nos transectos há seis pontos de medição itinerante que coincidem com seis pontos fixos.

Posteriormente os dados de temperatura são comparados com os das observações diárias, da média mensal (com a média de todas as medições obtidas no mês) e das diferenças na temperatura intra-urbana (diária e mensal). As diferenças da temperatura intra-urbana durante cada campanha são calculadas a partir da determinação da temperatura mínima observada em cada campanha. A partir disso é calculada a diferença do valor medido em cada ponto do transecto em relação ao ponto que apresentou o valor de mínima temperatura.

\section{Estabilidade atmosférica}

A caracterização da situação sinóptica à superfície nos dias de medição itinerante foi elaborada segundo o sistema de classificação modificado Pasquill-Gifford-Turner, PGT (Turner, 1970).

Esta classificação foi realizada a partir da análise dos dados da estação meteorológica localizada no campus da Glasgow Caledonian University $\left(55^{\circ} 47^{\prime} \mathrm{N}, 4^{\circ} 25^{\prime} \mathrm{W}\right.$, $138 \mathrm{~m}$ AMSL) no centro da cidade de Glasgow. As classes de estabilidade de A (fortemente instável) a G (fortemente estável) foram definidos de acordo com a Tabela 5. 
Tabela 5. Classes PGT de Estabilidade Atmosférica

\begin{tabular}{cccccccc}
\hline $\begin{array}{c}\text { VV } \\
(\mathrm{m} / \mathrm{s})\end{array}$ & \multicolumn{3}{c}{ Dia $-\mathrm{RS}\left(\mathrm{W} / \mathrm{m}^{2}\right)$} & \multicolumn{3}{c}{ Noite $-\mathrm{CN}$ (octas) } \\
& Elevado $^{1}$ & Moderado $^{2}$ & Baixo $^{3}$ & Nublado & Baixo $^{4}$ & Moderado $^{5}$ & Elevado $^{6}$ \\
\hline$\leq 2$ & A & A-B & B & C & G-F & F & D \\
$2-3$ & A-B & B & C & C & F & E & D \\
$3-5$ & B & B-C & C & C & E & D & D \\
$5-6$ & C & C-D & D & D & D & D & D \\
$>6$ & C & D & D & D & D & D & D \\
\hline
\end{tabular}

Legenda: VV velocidade do vento, RS radiação solar global, CN Cobertura noturna de nuvens, ${ }^{1}(>600)$, ${ }^{2}(300-600),{ }^{3}(<300),{ }^{4}(0-3),{ }^{5}(4-7),{ }^{6}(8)$, A (Fortemente instável ou convectivo), B (Moderadamente instável), C (Ligeiramente instável), D (Neutra), E (Ligeiramente estável), e F (Moderadamente estável), G (Fortemente estável).

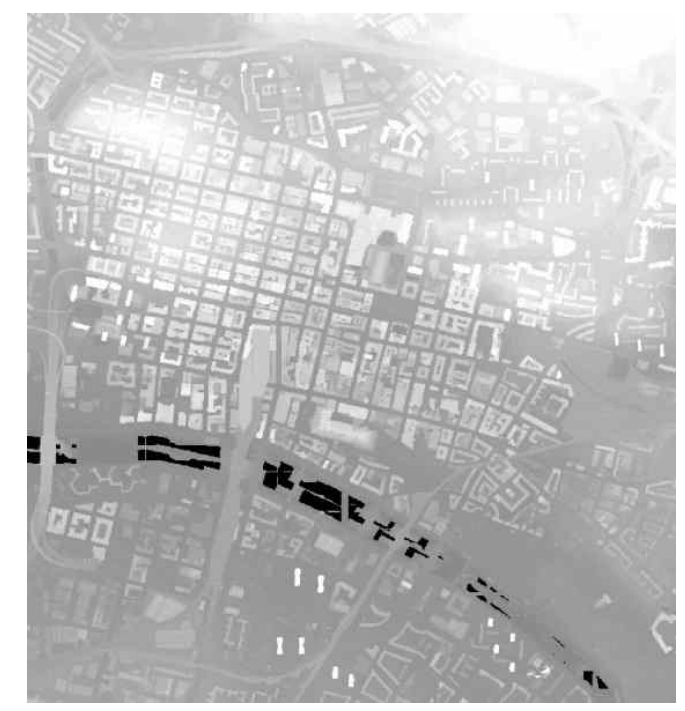

Figura 4. Mapas: (a) Mapa Lidar e (b) mapa com as edificações.
Representação espacial das variações de temperatura

Os pontos de medição georreferenciados utilizando um manual GPS (GPS Garmin $M A P)$, foram cartografados no mapa da cidade de Glasgow utilizando a ferramenta ArcMap do software ArcGIS (ArcGIS v. 10.1). Para a visualização foi utilizada uma combinação do mapa Lidar (Edinburgh University, 2013) e do mapa com as edificações (VECTOR MAP, Landmap Spatial Discovery, 2013). As Figuras 4a e $4 \mathrm{~b}$ mostram esses mapas, respectivamente.

Para cada dia de medição foram gerados mapas da distribuição do campo de temperatura para o centro da cidade de Glasgow. A Figura 5 apresenta, a título de

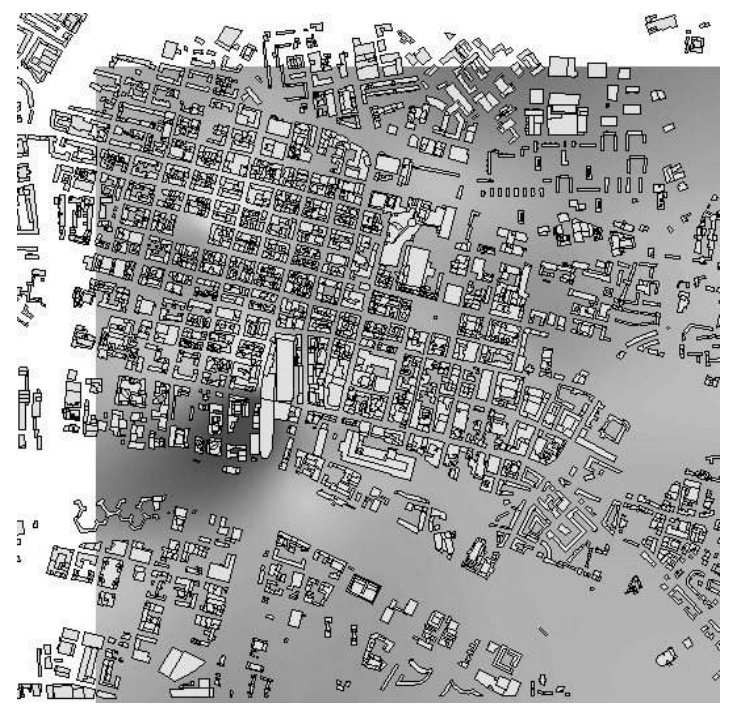

exemplo, a visualização das variações da temperatura intra-urbana e dos valores de SVF para cada ponto de medição, no dia 19 de Julho de 2013.

\section{Representação espacial das variações de temperatura intra-urbana}

Os mapas gerados para cada campanha e para as médias mensais revelaram-se uma ferramenta importante e útil para visualizar as tendências do comportamento da temperatura no meio intra-urbana de Glasgow.

Veja-se, por exemplo, que os resultados apresentados na Figura 6 e que mostram a relação entre o SVF e as temperaturas 


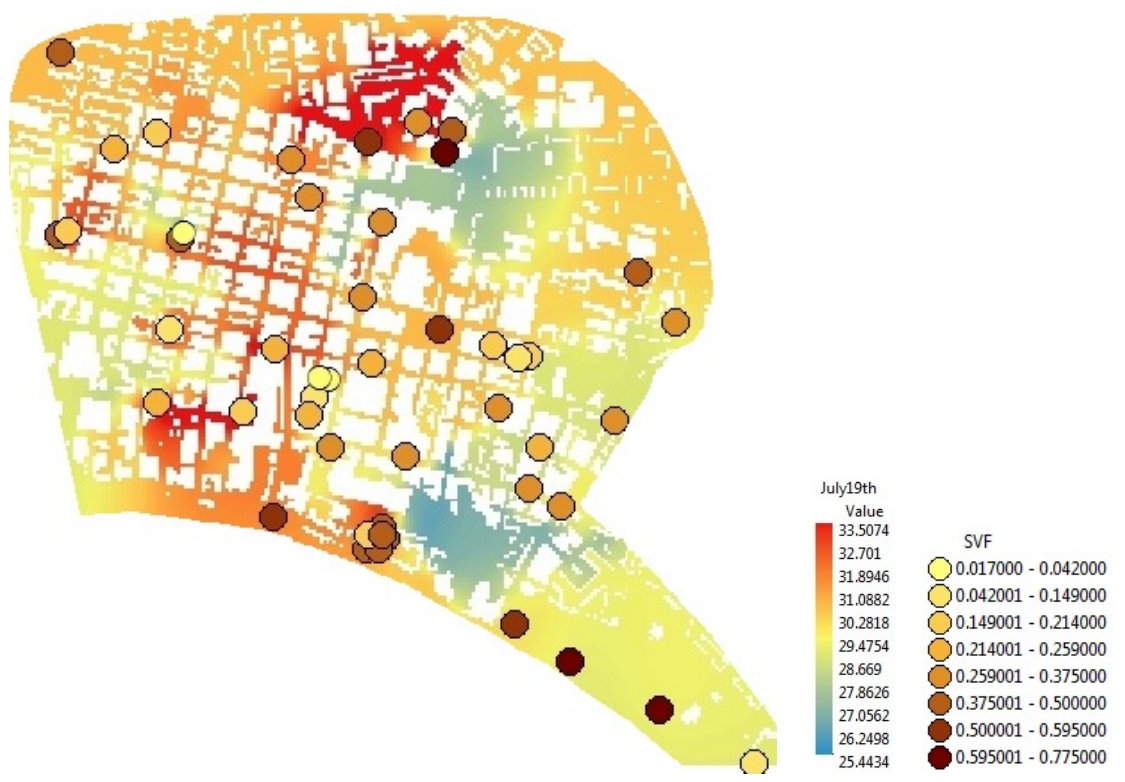

Figura 5. Mapa com a temperatura do ar e SVF - 19 de Julho de 2013.
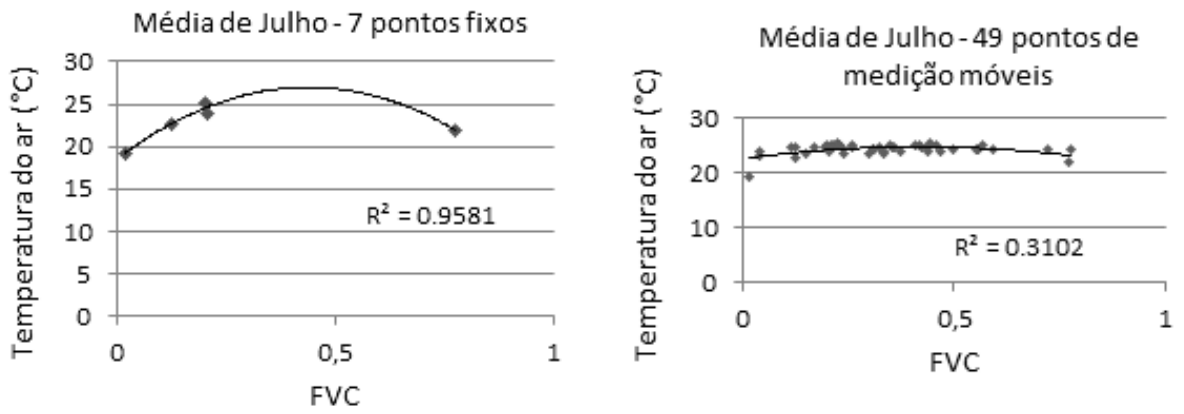

Figura 6. Temperatura do ar versus SVF para os dados da média do mês de Julho: (a) sete pontos fixos e (b) 49 pontos de medição.

médias das medições itinerantes e dos pontos fixos realizadas durante o mês de Julho de 2013 onde o $\mathrm{R}^{2}=0.95$ é bastante animador. Todavia, este excelente resultado pode dever-se ao tamanho da amostra que contava com apenas sete pontos de medição fixos. Não obstante, estes resultados confirmam as expectativas em relação à configuração da curva de forma parabólica com os valores mais baixos de temperatura encontrados nos valores de SVF elevados.

Quando incluimos o conjunto total de 49 pontos de medição (Figura 6b) os resultados indicam que os pontos extremos de SVF, conforme esperado, continuam apresentando as menores temperaturas do conjunto, apesar do valor de $\mathrm{R}^{2}$ ser bastante mais baixo.

Foram construídos vários mapas e gráficos de temperatura do ar versus SVF para cada dia e para as médias mensais. Os resultados apresentados na Figura 7 mostram mapas da variação espacial da temperatura intra-urbana em dois dias particularmente quentes, 18 e 22 de Julho de 2013. E aqui, as temperaturas extremas, ou seja, os valores de máxima e mínima temperatura medidas durante a campanha, para estes dois dias estavam atendendo à mesma distribuição espacial.

A área com as temperaturas mais elevadas para ambas as imagens está indicada por sua imagem do SVF na parte superior das Figuras $7 \mathrm{a}$ e $7 \mathrm{~b}(\mathrm{SVF}=0.569)$. A região com as temperaturas mais baixas $(\mathrm{SVF}=0.440)$ está indicada pelas imagens do SVF nas proximidades do Rio Clyde. 


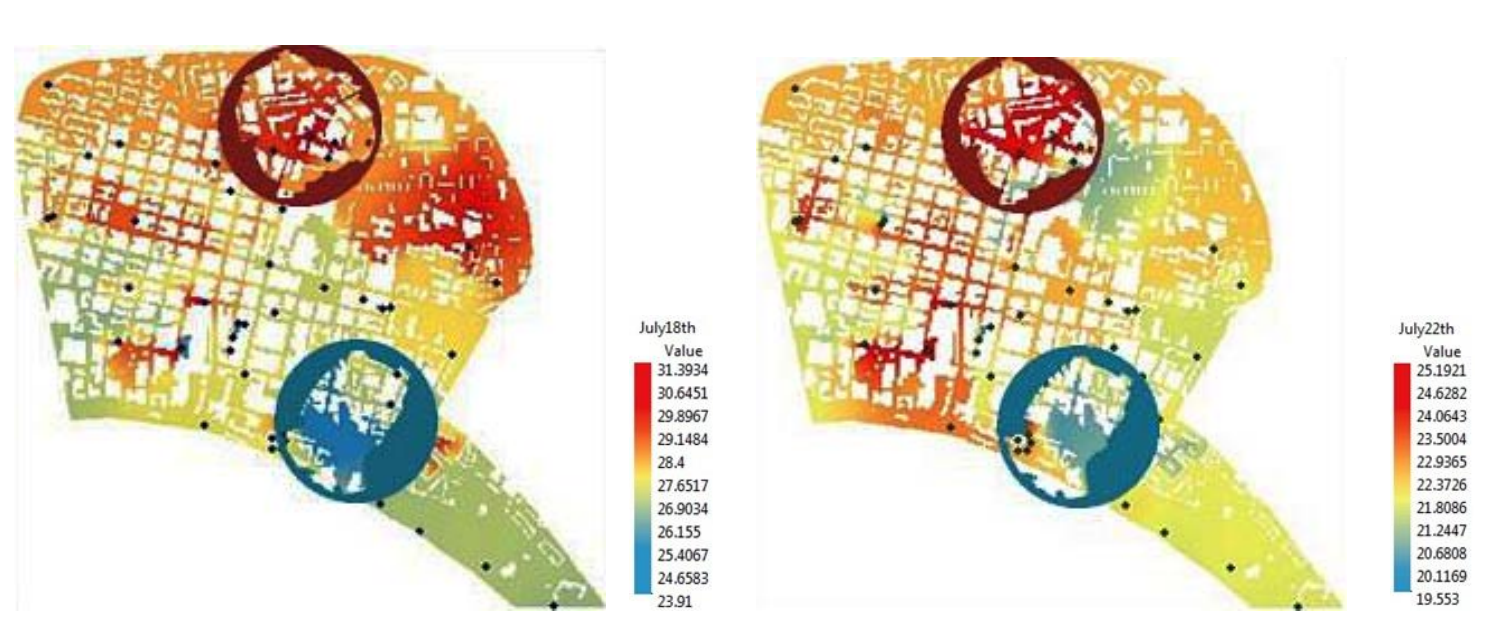

Figura 7. Variação especial da temperatura intra-urbana em dois dias particularmente quentes: 18 (a) e 22 (b) de Julho.
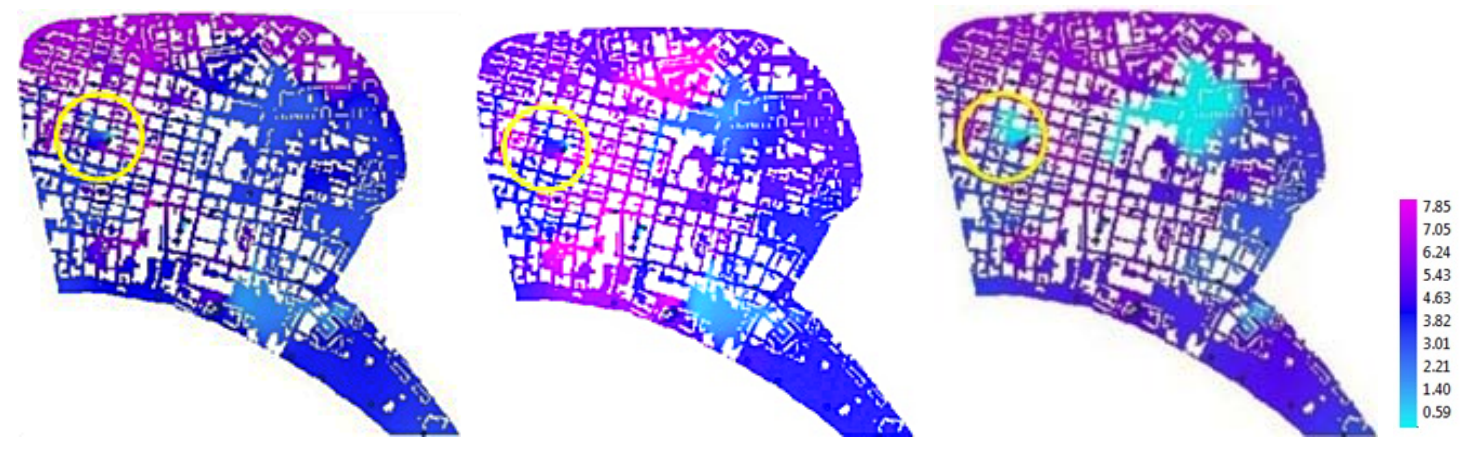

Figura 8. Diferenças da temperatura intra-urbana $\left({ }^{\circ} \mathrm{C}\right): 19$ (a) e 22 (b) de Julho e média mensal de Julho (c).

\section{Diferença de temperatura intra-urbana}

Para cada campanha de medição também é incluído o cálculo da diferença de temperatura (denominada aqui como diferença de temperatura intra-urbana) entre todos os pontos medidos, complementando assim a análise do comportamento do campo de temperatura. Para tal é calculado o ponto com o mínimo valor de temperatura medido, que é tomado como referência. Esse procedimento permite detectar a dimensão da variação da temperatura na área de estudo.

A partir das imagens é possível ressaltar que o padrão de diferença de temperatura manteve-se semelhante para a maior parte dos dias de campanha: a região próxima ao Rio Clyde, bem como um pequeno parque urbano, Blythswood Square (região assinalada com o círculo), estava entre os pontos onde foram observadas as temperaturas mais baixas. Na Figura 8 são apresentados os mapas com as diferenças na temperatura intra-urbana para os dias 19 (a) e 22 (b) de Julho, bem como para a média mensal (c) do mesmo mês.

Como forma de explorar a possibilidade de estabelecer uma relação significativa entre as condições meteorológicas e a variação da temperatura intra-urbana, a classe estabilidade atmosférica PGT foi adotada para classificação dos dias medidos conforme descrito anteriormente (Tabela 4).

Os resultados, no sentido de estabelecer uma relação significativa entre as condições meteorológicas e a variação da temperatura intra-urbana, não foram conclusivos como pode ser observado na Figura 9. Os valores de classes $\mathrm{A}$ e $\mathrm{C}$ têm uma distribuição extensa, se comparados com os resultados de classes $\mathrm{B}$ e $\mathrm{AB}$ que continuam a apresentar os valores de temperatura mais baixos nos 


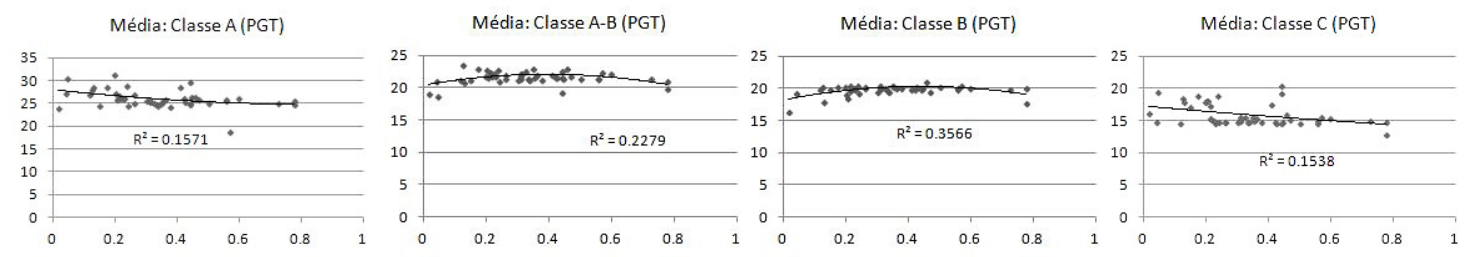

Figura 9. SVF versus temperaturas medidas e classificadas de acordo com as classes PGT: (a) A, (b) A-B, (c) B e (d) C.

Tabela 6. Diferenças de temperatura intra-urbana versus estabilidade atmosférica (Classe PGT)

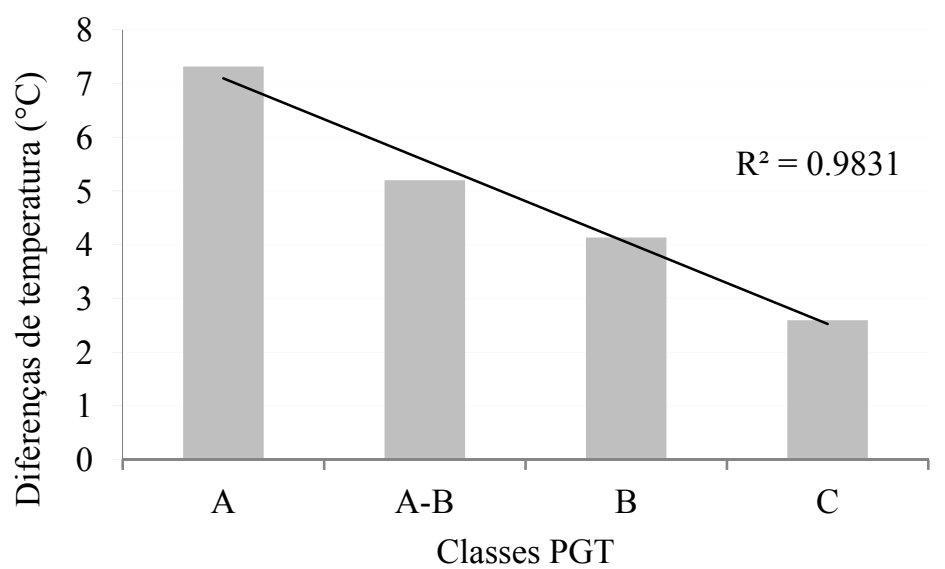

valores extremos de SVF. Não foram observadas diferenças ou tendências importantes que os diferenciasse sobremaneira daqueles obtidos relacionando SVF versus temperatura.

\section{Resultados e discussão}

A diferença das temperaturas intra-urbanas, conforme mencionado anteriormente, apresentou importantes alterações entre as campanhas de medição. Estas diferenças chegaram a variar entre 1,96 e $7,70^{\circ} \mathrm{C}$ e foi constatado um importante efeito das classes de estabilidade atmosférica sobre as diferenças de temperaturas intra-urbanas.

A Tabela 6 apresenta a relação entre a diferença de temperatura intra-urbana e a estabilidade atmosférica com os dados diários agrupados de acordo com as classes PGT. Pode-se observar que a presença de uma classe altamente instável (A) está associada às maiores diferenças de temperatura intra-urbanas no centro da cidade de Glasgow. Quanto mais instável a atmosfera maior é a variação de temperatura intra-urbana e da mesma forma, à medida que a estabilidade atmosférica aumenta, a variação da temperatura intra-urbana experimenta uma redução.

A Tabela 7 apresenta as médias das diferenças de temperatura intra-urbanas agrupadas por classes de estabilidade atmosférica (PGT) em sua distribuição espacial (ArcGIS) e com o gráfico de dispersão. Todos os mapas são apresentados na mesma escala de temperatura.

Duas observações são imediatas: as variações de temperatura intra-urbana estão claramente relacionadas com a estabilidade atmosférica (as menores diferenças de temperatura intra-urbana estão presentes nos dias de classificação 'ligeiramente instável' e as maiores diferenças ocorrem para os dias classificados como fortemente instáveis ou convectivos). A relação entre o SVF e as diferenças de temperatura intra-urbana são 
Tabela 7. Mapas das médias das diferenças de temperatura intra-urbanas (classes PGT) e gráficos de dispersão das médias das diferenças de temperatura versus SVF

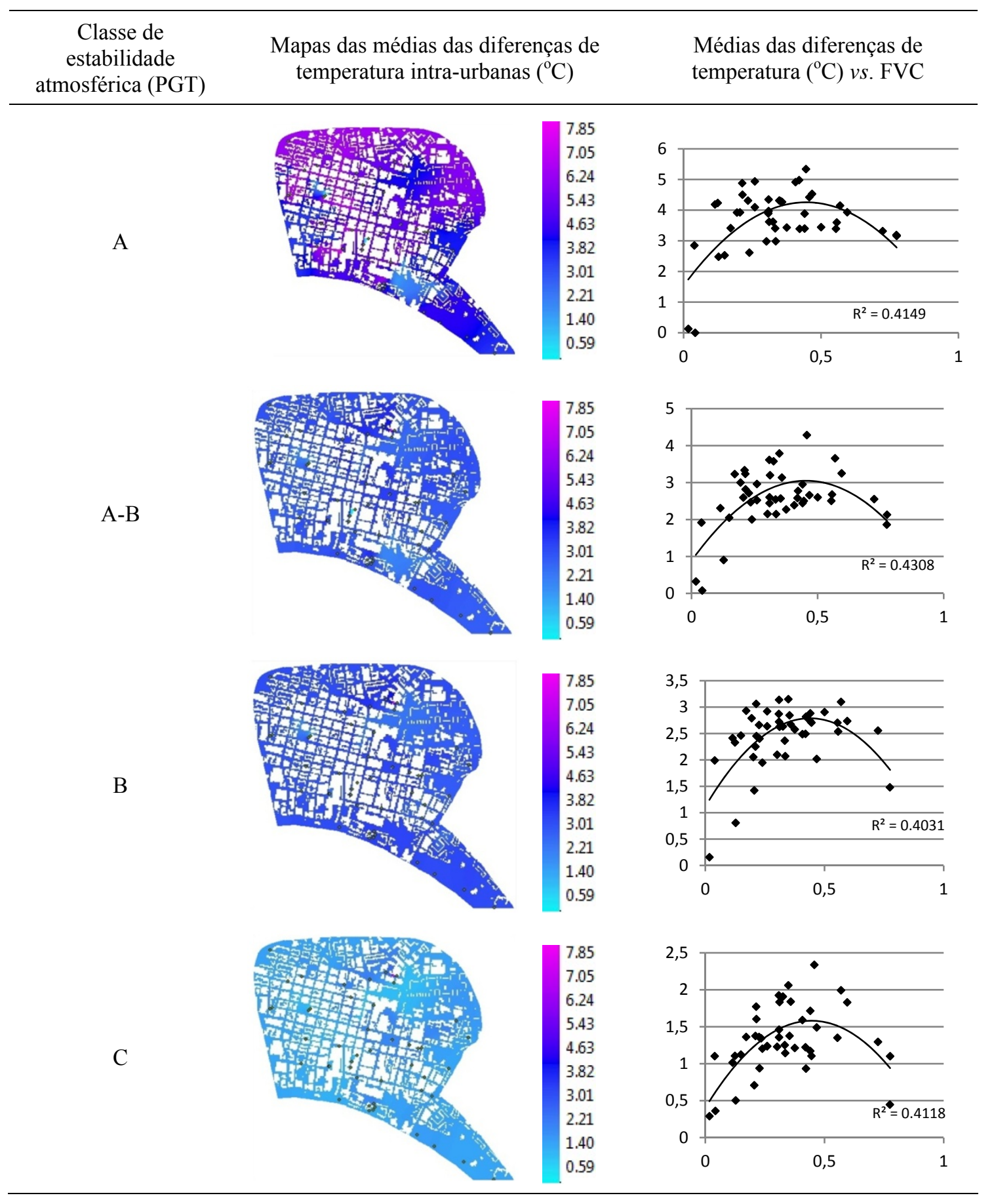

semelhantes para todas as classes de estabilidade atmosférica com o intervalo de $\mathrm{R}^{2}=0,4031-0,4308$.

A forma urbana, bem como os materiais de revestimento urbano, influenciam as variações de temperaturas locais em cidades. Conhecer suas respectivas contribuições às variações das temperaturas locais é importante condição para elaborar estratégias de planejamento urbano, capazes de lidar eficazmente com o problema de superaquecimento urbano.

Os padrões espaciais das variações da temperatura intra-urbana mostram que as regiões próximas aos rios, canais, praças e parques urbanos apresentam variações de 

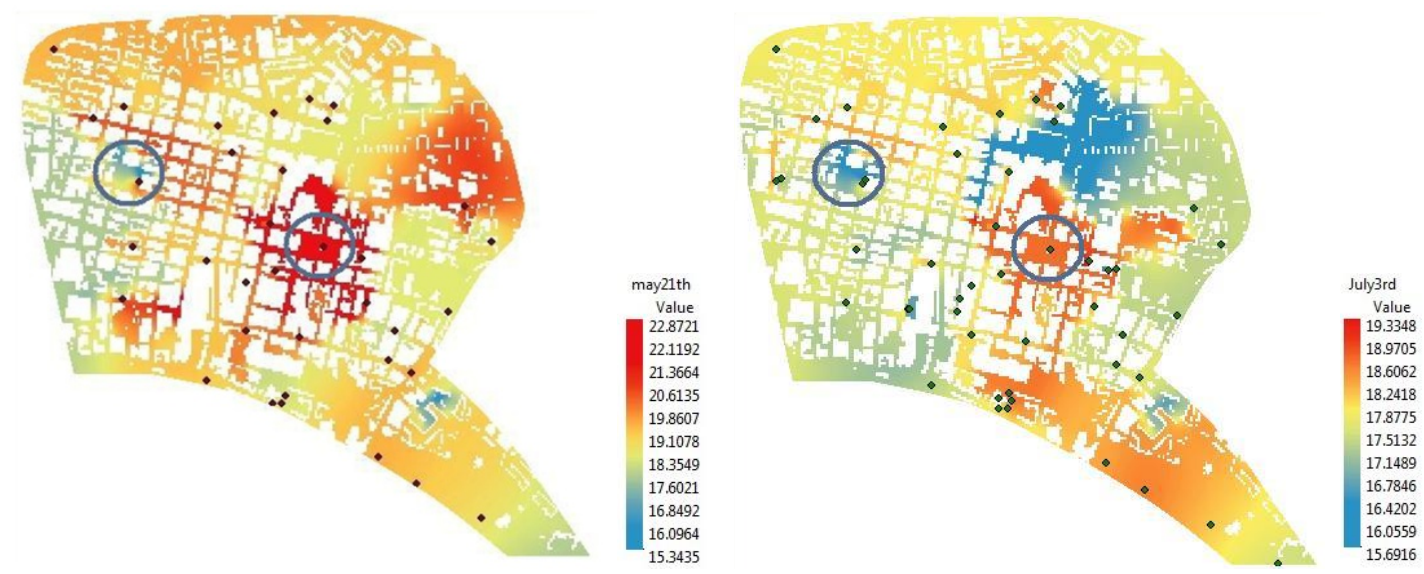

Figura 10. Diferenças de temperatura intra-urbana em duas praças da cidade de Glasgow: (a) dia 21 de Maio e (b) 3 de Julho de 2013.

temperatura consistentemente inferiores conforme apresentado na Figura 8. Nas figuras $10 \mathrm{a}$ e $10 \mathrm{~b}$ os resultados medidos para duas praças da cidade, uma arborizada e outra não, respectivamente, permitem observar a diferença da temperatura medida. É interessante observar que no dia 21 de Maio de 2013 (Figura 10a) a diferença de temperatura quase atinge $4^{\circ} \mathrm{C}$ e no dia 3 e Julho de 2013 (Figura 10b) fica entorno dos $2{ }^{\circ} \mathrm{C}$.

Observa-se que, mesmo para os parques urbanos, a presença de diferentes materiais de revestimento urbano representa alterações significativas da temperatura local. A adoção de estratégias de inserção de vegetação também pode resultar em uma maior oferta de áreas abertas e verdes para a população, contribuindo para a melhoria da qualidade de vida. No entanto, nem sempre é viável a introdução de espaços livres abertos em todos os lugares, tornando a opção por grandes espaços verdes, por vezes impraticável. O estudo do papel da vegetação e dos corpos de água, bem como de seu efeito de mitigação requer uma análise mais aprofundada que está sendo desenvolvida pelos autores. Sabendo-se que os efeitos obtidos com a adoção de áreas de vegetação dependem também do tipo de vegetação e de sua distribuição, esse tema merece ser mais investigado e o emprego da simulação computacional pode constituir-se em uma importante e eficaz ferramenta.

Buscando estabelecer relações entre a forma urbana, a dinâmica do campo de temperatura intra-urbana e possíveis conexões com a instabilidade atmosférica para cidades de clima tropical, pesquisa semelhante está em andamento para as cidades do Rio de Janeiro e de Petrópolis. Os primeiros resultados parecem confirmar a importância das áreas verdes e sua interferência na temperatura intra-urbana produzindo um efeito de resfriamento.

\section{Conclusões}

As condições atmosféricas, bem como a forma urbana, influenciam as variações de temperaturas locais em cidades. Conhecer suas respectivas contribuições às variações das temperaturas locais é importante condição para elaborar estratégias de planejamento urbano capazes de lidar eficazmente com o problema de superaquecimento urbano.

A relação entre a forma urbana (aqui medida pelo SVF) e as variações de temperatura intra-urbanas, mesmo sendo um dos aspectos mais bem estudados em pesquisas de ilha de calor urbanas, não parece tão evidente.

A estabilidade atmosférica, definida pelo sistema de classificação modificado PGT, indica interferência na relação entre o SVF e a temperatura intra-urbana, mas esta relação também necessita ser mais investigada. O fator de visão do céu, SVF, parece apresentar uma relação 'parabólica' com a temperatura do ar medida durante o dia (espaços muito abertos como áreas verdes, bem como aqueles densamente construídos, com locais 
sombreados, que apresentam as temperaturas mais baixas), mas essa relação não é conclusiva.

O presente trabalho sugere que a ocorrência de diferenças de temperatura intra-urbanas mais elevadas (ou seja, diferença de temperatura entre os pontos mais frios e os mais quentes de uma determinada região urbana) está fortemente relacionada com a estabilidade atmosférica.

As classes de estabilidade atmosférica mais instáveis têm as maiores variações de temperaturas intra-urbanas enquanto as classes menos instáveis apresentam variações menores. A partir da categorização dos dias de medição de acordo com as classes PGT, a estabilidade atmosférica parece ser capaz de explicar cerca de metade das variações nas temperaturas intra-urbanas.

Os padrões espaciais das variações de temperatura locais mostram consistentemente que corpos de água e parques urbanos têm variações de temperatura consistentemente inferiores. Os resultados também indicam que vegetação e material de cobertura urbana podem desempenhar um papel importante quando incluídos nestas análises.

Um maior entendimento acerca da influência da forma urbana nas variações das temperaturas locais pode ser um fator de importante auxílio para elaboração de estratégias de planejamento apropriadas para mitigar ou lidar com o superaquecimento urbano num futuro próximo, ante as perspectivas de aquecimento global.

\section{Agradecimentos}

Patricia R. C. Drach agradece o suporte financeiro do Conselho Nacional de Desenvolvimento Científico e Tecnológico $(\mathrm{CNPq})$, agência do Ministério da Ciência, Tecnologia e Inovação (MCTI) (246551/2012-7) e o apoio da Glasgow Caledonian University, Reino Unido.

\section{Referências}

Amorim, M., Lima Neto, J. e Monteiro, A. (2013) Climatologia urbana e regional: questões teóricas e estudos de caso (Outras Expressões, São Paulo).

Chandler, A. J. (1965) The climate of London,
(Hutchinson and Co, Londres).

Corbella, O. e Yannas, S. (2003) Em busca de uma arquitetura sustentável para os Trópicos: conforto ambiental (FAPERJ Revan, Rio de Janeiro).

Drach, P. R. C. (2007) Modelagem computacional e simulação numérica em arquitetura visando conforto em ambientes construídos. Tese de Doutoramento não publicada, Laboratório Nacional de Computação Científica, Brasil.

Greater London Authority, GLA (2006) London's urban heat island: a summary for decision makers, (http://legacy.london.gov.uk/ mayor /environment /climate-change /docs /UHI_summary_report.pdf) consultado em 31 de Dezembro de 2013.

Greater London Authority, GLA (2011) Managing risks and increasing resilience: the Mayor's climate change adaptation strategy (http://www.london.gov.uk/priorities/environ ment /publications /managing-risks-andincreasing-resilience-the-mayor-s-climate) consultado em 31 de Dezembro de 2013.

Hebbert, M. e Jankovic, V. (2013) 'Cities and climate change: the precedents and why they matter', Urban Studies 50, 1332-47.

Holmer, B., Thorsson, S. e Lindén, J. (2012) 'Evening evapotranspirative cooling in relation to vegetation and urban geometry in the city of Ouagadougou, Burkina Faso', International Journal of Climatology 33, 3089-105.

Kershaw, T., Sanderson, M., Coley, D. e Eames, M. (2010) 'Estimation of the urbanheat island for UK climate change projections', Building Services Engineering Research and Technology 31, 251-63.

Kleerekoper, L., van Esch, M. e Salcedo, T. B. (2012) 'How to make a city climate-proof, addressing the urban heat island effect', Resources, Conservation and Recycling 64, 30-8.

Kolokotroni, M. e Giridharan, R. (2008) 'Urban heat island intensity in London: An investigation of the impact of physical characteristics on changes in outdoor air temperature during summer', Solar Energy 82, 986-98.

Kolokotsa, D., Psomas, A. e Karapidakis, E. (2009) 'Urban heat island in southern Europe: The case study of Hania, Crete', Solar Energy 83, 1871-83.

Krüger, E. L. e Emmanuel, R. (2013) 'Accounting for atmospheric stability conditions in Urban Heat Island studies: the case of Glasgow, UK', Landscape and Urban Planning 117, 112-21.

Lai, L. e Cheng, W. (2009) 'Air quality influenced by urban heat island coupled with 
synoptic weather patterns', Science of the Total Environment 407, 2724-33.

Lee, S., Lee, K., Jin, W. e Song, H. (2009) 'Effect of an urban park on air temperature differences in a central business district area', Landscape and Ecological Engineering 5, 183-91.

Matzarakis, A., Rutz, F. e Mayer, H. (2010) 'Modelling radiation fluxes in simple and complex environments: basics of the RayMan model', International Journal of Biometeorology 54, 131-9.

Mavrogianni, A., Davies, M. e Batty, M. (2011) 'The comfort, energy and health implications of London's urban heat island', Building Services Engineering Research and Technology 32, 35-52.

Mirzaei, P. A. e Haghighat, F. (2010) 'Approaches to study Urban Heat Island abilities and limitations', Building and Environment 45, 2192-201.

Monteiro, A., Velho, S. e Gois, J. (2012) 'A importância da fragmentação das paisagens urbanas na Grande Área Metropolitana do Porto para a modelização das ilhas de calor urbano - uma abordagem metodológica', Revista da Faculdade de Letras da FLUP 1:III, 123-59.

Monteiro, A., Carvalho, V. e Sousa, C. (2012) 'Excess mortality and morbidity during July 2006 heat wave in Porto, Portugal - TMRT efficiency to anticipate negative effects on health', 8th International Conference on Urban Climate, Dublin, 6 a 10 de Agosto.

Oke, T. R. (1981) 'Canyon geometry and the nocturnal urban heat island: comparison of scale model and field observations', International Journal of Climatology 1, 237-
54.

Shimoda, Y. (2003) 'Adaptation measures for climate change and the urban heat island in Japan's built environment', Building Research \& Information 31, 222-30.

Stone, B., Vargo, J. e Habeeb, D. (2012) 'Managing climate change in cities: Will climate action plans work?', Landscape and Urban Planning 107, 263-71.

Svensson, M. K. (2004) 'Sky view factor analysis - implications for urban air temperature differences', Meteorological Applications 11, 201-11.

Tomlinson, C. J., Chapman, L., Thornes, J. E. e Baker, C. J. (2012) 'Derivation of Birmingham's summer surface urban heat island from MODIS satellite images', International Journal of Climatology 32, 2214-42.

Turner, D. B. (1970) Workbook of atmospheric dispersion estimates (Environmental Protection Agency, Washinghton).

Unger, J., Sümeghy, Z., Gulyás, Á., Bottyán, Z. e Mucsi, L. (2001) 'Land-use and meteorological aspects of the urban heat island', Meteorological Applications 8, 18994.

Unger, J. (2004) 'Intra-urban relationship between surface geometry and urban heat island: review and new approach', Climate Research 27, 253-64.

Unger, J. (2009) 'Connection between urban heat island and sky view factor approximated by a software tool on a 3D urban database', International Journal of Environment and Pollution 36, 59-80.

United Nations, UN (2011) World Urbanization Prospects (United Nations, Nova Iorque).

\title{
Tradução do título, resumo e palavras-chave
}

\section{The influence of urban form on intra-urban temperature}

\begin{abstract}
Climate change, and its consequences, points out the need of developing strategies for mitigating problems related to urban overheating. This paper aims to examine the influence of urban form, here measured by the Sky View Factor (SVF), on intra-urban temperature in the city of Glasgow, UK, a naturally cold city. A set of 49 measurement points was selected in the city centre, and 31 campaigns, for data collection, were made during the spring and summer of 2013. In order to cover a large area of the city, within a relatively short period of time, the 'traverse' method was used on predetermined routes. Temperature variation was visualized using the software ArcGIS. The results indicate that the maximum intra-urban temperature differences are strongly correlated with atmospheric stability, which suggests that atmospheric stability has a relevant effect on intra-urban temperature variation. The study also indicates, as expected, that the vegetation and the urban cover materials play an important role in influencing the local climate in cold cities. The knowledge on the influence of urban form on local temperature variation can be important in the development of strategies to deal with urban overheating.
\end{abstract}

Keywords: intra-urban temperature, urban form, Sky View Factor, urban design, atmospheric stability 